\title{
Antimicrobial resistance in commensal Escherichia coli and Enterococcus spp. is influenced by production system, antimicrobial use, and biosecurity measures on Spanish pig farms
}

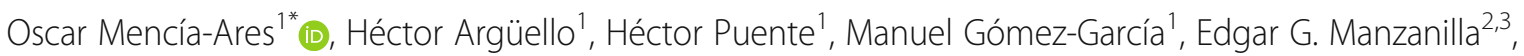
Avelino Álvarez-Ordóñez ${ }^{4,5}$, Ana Carvajal ${ }^{1}$ and Pedro Rubio ${ }^{1}$

\begin{abstract}
Background: Antimicrobial resistance (AMR) is a global public health threat consequence of antimicrobial use (AMU) in human and animal medicine. In food-producing animals factors such as management, husbandry or biosecurity may impact AMU. Organic and extensive Iberian swine productions are based on a more sustainable and eco-friendly management system, providing an excellent opportunity to evaluate how sustained differences in AMU impact the AMR in indicator bacteria. Here, we evaluate the usefulness of commensal Escherichia coli and Enterococcus spp. isolates as AMR bioindicators when comparing 37 Spanish pig farms from both intensive and organic-extensive production systems, considering the effect of AMU and biosecurity measures, the last only on intensive farms.

Results: The production system was the main factor contributing to explain the AMR differences in E. coli and Enterococcus spp. In both bacteria, the pansusceptible phenotype was more common $(p<0.001)$ on organicextensive farms when compared to intensive herds. The microbiological resistance in commensal $E$. coli was, for most of the antimicrobials evaluated, significantly higher $(p<0.05)$ on intensive farms. In enterococci, the lincosamides usage revealed the association between AMR and AMU, with an increase in the AMR for erythromycin $(p<0.01)$, quinupristin-dalfopristin $(p<0.01)$ and the multidrug-resistant (MDR) phenotype $(p<0.05)$. The biosecurity measures implemented on intensive farms influenced the AMR of these bioindicators, with a slightly lower resistance to sulfamethoxazole $(p<0.01)$ and the MDR phenotype $(p<0.05)$ in $E$. coli isolated from farms with better cleaning and disinfection protocols. On these intensive farms, we also observed that larger herds had a higher biosecurity when compared to smaller farms $(p<0.01)$, with no significant associations between AMU and the biosecurity scores.

(Continued on next page)
\end{abstract}

\footnotetext{
* Correspondence: oscar.mencia@unileon.es

'Department of Animal Health, Faculty of Veterinary, Universidad de León, León, Spain

Full list of author information is available at the end of the article
}

(c) The Author(s). 2021 Open Access This article is licensed under a Creative Commons Attribution 4.0 International License, which permits use, sharing, adaptation, distribution and reproduction in any medium or format, as long as you give appropriate credit to the original author(s) and the source, provide a link to the Creative Commons licence, and indicate if changes were made. The images or other third party material in this article are included in the article's Creative Commons licence, unless indicated otherwise in a credit line to the material. If material is not included in the article's Creative Commons licence and your intended use is not permitted by statutory regulation or exceeds the permitted use, you will need to obtain permission directly from the copyright holder. To view a copy of this licence, visit http://creativecommons.org/licenses/by/4.0/ The Creative Commons Public Domain Dedication waiver (http://creativecommons.org/publicdomain/zero/1.0/) applies to the data made available in this article, unless otherwise stated in a credit line to the data. 
(Continued from previous page)

Conclusions: Overall, this study evidences that the production system and, to a lesser extent, the biosecurity measures, contribute to the AMR development in commensal E. coli and Enterococcus spp., with antimicrobial usage as the main differential factor, and demonstrates the potential value of these bacteria as bioindicators on pig farms in AMR surveillance programs.

Keywords: Antibiotic usage, Bioindicator, Enterococcus spp., Escherichia coli, One health, Swine, Sustainable farming

\section{Background}

Antimicrobial resistance (AMR) is one of the largest threats to global health and food security [1]. The most important single factor that leads to AMR is antimicrobial use (AMU) [2] and, although its use in human medicine is the main driver of AMR, AMU in veterinary medicine also contributes to the burden of AMR in human health [3]. The long-term AMU in food-producing animals facilitates the development and spread of AMR bacteria through food, water or slurry, which is used as fertilizer. In fact, similarities among AMR bacteria in humans and animals have been observed in foodborne pathogens and commensal bacteria, such as E. coli, Enterococcus spp. or Salmonella spp. [4].

Despite antimicrobials are essential in bacterial diseases treatments [5], current policies aim at reducing AMU in livestock [6], particularly in the swine industry, which is the most extensive agricultural user of antimicrobials in the European Union [7, 8]. In this sense, the AMR surveillance in targeted zoonotic or bioindicator bacteria through European programs [9] constitutes a fundamental pillar in the evaluation of the trends in AMR due to antimicrobial selection pressure [10].

Reductions in AMU may be achieved through the improvement of vaccination programs and biosecurity standards [11, 12], and strategies which involve animal husbandry and welfare, such as alternative farming systems as it has been observed on organic pig farms [13]. In this sense, within the Spanish swine production, the extensive system is a traditional and sustainable production system associated with the Iberian pig which uses natural resources and integrates pig production into an oak field ecosystem [14]. Thus, this management system provides an excellent opportunity to compare AMR patterns in potential bioindicator bacteria in pigs and farm environments compared to those of intensive production farms. Hence, this study aims at determining the fitting of Escherichia coli and Enterococcus spp. isolates as AMR bioindicator species in a comparative study between intensive and organic-extensive Spanish swine herds, considering AMU and biosecurity score, the last only on intensive pig farms.

\section{Methods}

Farm selection and sample collection

A total of 37 swine farms were selected from different Spanish regions and according to their productions system to represent a convenience sample of Spanish intensive (18 herds), extensive (12 herds) and organic (7 herds) management systems. Organic and extensive farms were merged into a single category as organic herds were mainly converted from extensive farms, rearing Iberian pig on a system based on the use of natural resources in farrow-to-finish farms. Thus, the farms were grouped into intensive (18 herds) and organicextensive (19 herds) for further analyses.

Sampling and farm characteristics are detailed in Mencía-Ares et al. [15]. Briefly, sampling was carried out from 2017 to 2018 in pigs in the last month of the fattening period, with no antimicrobial treatment in the immediate month prior to the sampling. On each fattening unit, faeces, environmental swabs and slurry, when available, were collected.

\section{Antimicrobial use}

The veterinary practitioner responsible for each farm recorded AMU on the pigs in the sampled fattening unit during the immediate four-month period prior to sampling. This record was based on the register of treatments. Antimicrobial use was categorized into 13 classes: (i) total, (ii) penicillins, (iii), third generation cephalosporins, (iv) aminoglycosides, (v) macrolides, (vi) lincosamides, (vii) quinolones, (viii) tetracyclines, (ix) phenicols, (x) polymyxins, (xi) sulfonamides, (xii) diaminopyrimidines, and (xiii) pleuromutilins. For each antimicrobial class, usage per farm was expressed in annual $\mathrm{mg} / \mathrm{PCU}$, following the European Surveillance of Veterinary Antimicrobial Consumption (ESVAC) protocol [16]. Total AMU per farm was calculated as the sum of the individual contributions of each antimicrobial class on each farm.

\section{Bacterial isolation and characterization}

Escherichia coli isolation was performed with a direct inoculation of the samples with a swab in MacConkey agar (Scharlau, Sentmenat, Spain) at $37{ }^{\circ} \mathrm{C}$ for $24 \mathrm{~h}$. Presumptive colonies were subcultured in tryptic soy agar (Scharlau, Sentmenat, Spain) at $37^{\circ} \mathrm{C}$ for $24 \mathrm{~h}$. 
Samples were directly inoculated with a swab in Slanetz and Bartley agar (Oxoid, Basingstoke, UK) at $37^{\circ} \mathrm{C}$ for $48 \mathrm{~h}$ for Enterococcus spp., isolation. Dark pink colonies were subcultured in bile esculin azide agar (Merck, Darmstadt, Germany) at $44^{\circ} \mathrm{C}$ for $4 \mathrm{~h}$ for Enterococcus confirmation. Presumptive colonies were subcultured in brain heart infusion (BHI) agar (Merck, Darmstadt, Germany) at $37^{\circ} \mathrm{C}$ for $24 \mathrm{~h}$.

E. coli and Enterococcus presumptive isolates were confirmed and characterized at species level, respectively, with MALDI-TOF mass spectrometry using the IVD MALDI Biotyper (Bruker Daltonik, Bremen, Germany) and following the manufacturer's standard protocols.

\section{Antimicrobial susceptibility testing}

Antimicrobial susceptibility testing was conducted on a single isolate from each type of sample (faeces, slurry and environment) and an extra isolate randomly selected from any of the three sample types. The technique followed the procedures outlined by the European Committee on Antimicrobial Susceptibility Testing (EUCAST) [17]. The minimum inhibitory concentration (MIC) of the tested antimicrobials was determined using the broth microdilution method. The "microbiological" resistance was determined in accordance with the epidemiological cut-off value (ECOFF), thus dividing the microorganisms depending on whether they have (nonwild type, NWT) or not (wild type, WT) acquired resistance mechanisms to each antimicrobial [18]. Non-wild type and resistant phenotype will be indistinctly used throughout the study. Multidrug-resistance (MDR) was defined as acquired non-susceptibility to at least one agent in three or more antimicrobial classes [19]. A microorganism susceptible to all antimicrobials tested was defined as pansusceptible (PNS).

AMR in E. coli and Enterococcus spp. isolates was evaluated with EUVSEC and EUVENC Sensititre plates (TREK Diagnostic Systems, East Grinstead, UK), respectively. The antimicrobials evaluated and their ECOFFs are shown in Tables 1 and 2. Escherichia coli ATCC 25922 and Enterococcus faecalis ATCC 29212 were used as control strains, respectively.

Prior to testing, E. coli and Enterococcus spp. colonies cultured in $\mathrm{BHI}$ agar at $37^{\circ} \mathrm{C}$ for $24 \mathrm{~h}$ were suspended in $5 \mathrm{ml}$ of demineralized water to reach a turbidity of McFarland 0.5. Ten microliters of the bacterial suspension were transferred to $11 \mathrm{ml}$ of Mueller-Hinton broth (TREK Diagnostic Systems, East Grinstead, UK) and $50 \mu \mathrm{l}$ per well were dispensed with the Sensititre AIM Automated Inoculation Delivery System (TREK Diagnostic Systems, East Grinstead, UK). Plates were sealed and incubated in aerophilic atmosphere at $37^{\circ} \mathrm{C}$ for $24 \mathrm{~h}$.

\section{Biosecurity assessment}

To evaluate the biosecurity in the intensive herds, a preestablished protocol, the Biocheck.UGent ${ }^{\mathrm{tm}}$ scoring system, developed by Gent University [20], was used. A detailed description of this questionnaire can be accessed elsewhere [21-23]. Briefly, it contains 109 closed questions grouped into internal and external biosecurity, with six subcategories in each group. Each subcategory includes different practices and its score is given in a rank

Table 1 Minimum inhibitory concentrations (MICs) of 14 antimicrobials against 148 Escherichia coli isolates from animal and environmental samples recovered from swine farms. The thick line represents the epidemiological cut-off value (ECOFF) used for each antimicrobial to classify isolates into non-wild type (NWT) and wild type (WT). Areas in grey represent values outside the concentrations included in the broth microdilution method

\begin{tabular}{|c|c|c|c|c|c|c|c|c|c|c|c|c|c|c|c|c|c|c|c|c|c|c|}
\hline \multirow{2}{*}{${ }^{\mathrm{a}}$ Antimicrobial } & \multicolumn{18}{|c|}{$\mathrm{N}^{0}$ of isolates with MIC $(\mu \mathrm{g} / \mathrm{ml})$} & \multicolumn{2}{|c|}{ WT } & \multicolumn{2}{|c|}{ NWT } \\
\hline & $\leq 0.016$ & 0.03 & 0.06 & 0.12 & 0.25 & 0.5 & 1 & 2 & 4 & 8 & 16 & 32 & 64 & 128 & 256 & 512 & 1024 & $\geq 2048$ & $\mathbf{n}$ & $\%$ & n & $\%$ \\
\hline AMP & & & & & & & 4 & 28 & 32 & 2 & 0 & 1 & 2 & 79 & & & & & 66 & 44.6 & 82 & 55.4 \\
\hline FOT & & & & & 147 & 0 & 1 & 0 & 0 & & & & & & & & & & 147 & 99.3 & 1 & 0.7 \\
\hline TAZ & & & & & & 147 & 0 & 1 & 0 & 0 & & & & & & & & & 147 & 100 & 1 & 0.7 \\
\hline MERO & & 146 & 2 & 0 & 0 & 0 & 0 & 0 & 0 & 0 & 0 & & & & & & & & 148 & 100 & 0 & 0 \\
\hline GEN & & & & & & 110 & 23 & $7 \mid$ & 0 & 0 & 2 & 4 & 2 & & & & & & 140 & 94.6 & 8 & 5.4 \\
\hline AZI & & & & & & & & 17 & 73 & 50 & 5 & 2 & 0 & 1 & & & & & 145 & 98.0 & 3 & 2.0 \\
\hline TET & & & & & & & & 48 & 2 & 2 & 1 & 9 & 36 & 50 & & & & & 52 & 35.1 & 96 & 64.9 \\
\hline CIP & 71 & 51 & 2 & 3 & 12 & 3 & 1 & 0 & 0 & 0 & 5 & & & & & & & & 124 & 83.8 & 24 & 16.2 \\
\hline NAL & & & & & & & & & 120 & 14 & 2 & 1 & 0 & 2 & 9 & & & & 134 & 90.5 & 14 & 9.5 \\
\hline COL & & & & & & & 147 & 1 & 0 & 0 & 0 & & & & & & & & 148 & 100 & 0 & 0 \\
\hline SMX & & & & & & & & & & 50 & 17 & 5 & 1 & 0 & 0 & 0 & 4 & 71 & 73 & 49.3 & 75 & 50.7 \\
\hline TMP & & & & & 27 & 46 & 3 & $0 \mid$ & 0 & 0 & 0 & 0 & 72 & & & & & & 76 & 51.4 & 72 & 48.6 \\
\hline TGC & & & & & 143 & 5 & 0 & 0 & 0 & 0 & & & & & & & & & 148 & 100 & 0 & 0 \\
\hline CHL & & & & & & & & & & 101 & 3 & 7 & 12 & 10 & 15 & & & & 104 & 70.3 & 44 & 29.7 \\
\hline
\end{tabular}

${ }^{a}$ Antimicrobial: AMP Ampicillin, FOT Cefotaxime, TAZ Ceftazidime, MERO Meropenem, GEN Gentamicin, AZI Azithromycin, TET Tetracycline, CIP Ciprofloxacin, NAL Nalidixic acid, COL Colistin, SMX Sulfamethoxazole, TMP Trimethoprim, TGC Tigecycline, CHL Chloramphenicol 
Table 2 Minimum inhibitory concentrations (MICs) of 12 antimicrobials against 146 Enterococcus spp. isolates from animal and environmental samples recovered from swine farms. The thick line represents the epidemiological cut-off value (ECOFF) used for each antimicrobial to classify isolates into non-wild type (NWT) and wild type (WT). Areas in grey represent values outside the concentrations included in the broth microdilution method

\begin{tabular}{|c|c|c|c|c|c|c|c|c|c|c|c|c|c|c|c|c|c|c|c|c|c|}
\hline \multirow{2}{*}{${ }^{\mathrm{a}}$ Antimicrobial } & \multicolumn{17}{|c|}{$\mathrm{N}^{\circ}$ of isolates with MIC $(\mu \mathrm{g} / \mathrm{ml})$} & \multicolumn{2}{|c|}{ WT } & \multicolumn{2}{|c|}{ NWT } \\
\hline & 0.03 & 0.06 & 0.12 & 0.25 & 0.5 & 1 & 2 & 4 & 8 & 16 & 32 & 64 & 128 & 256 & 512 & 1024 & $\geq 2048$ & $\mathbf{n}$ & $\%$ & $\mathbf{n}$ & $\%$ \\
\hline AMP & & & & & 48 & 49 & 18 & 26 & 5 & 0 & 0 & 0 & & & & & & 141 & 96.6 & 5 & 3.4 \\
\hline GEN & & & & & & & & & 130 & 7 & 0 & $0 \mid$ & 1 & 2 & 0 & 1 & 5 & 137 & 93.8 & 9 & 6.2 \\
\hline ERY & & & & & & 59 & 24 & 6 & 3 & 0 & 1 & 0 & 1 & 52 & & & & 89 & 61.0 & 57 & 39.0 \\
\hline TET & & & & & & 31 & 0 & 0 & 0 & 1 & 1 & 16 & 35 & 62 & & & & 31 & 21.2 & 115 & 78.8 \\
\hline TGC & 6 & 25 & 70 & 39 & 5 & 1 & 0 & 0 & & & & & & & & & & 140 & 95.9 & 6 & 4.1 \\
\hline CIP & & & 0 & 9 & 27 & 55 & 28 & 22 & 0 & 4 & 1 & & & & & & & 141 & 96.6 & 5 & 3.4 \\
\hline VAN & & & & & & 131 & 14 & 1 & 0 & 0 & 0 & 0 & 0 & & & & & 146 & 100 & 0 & 0 \\
\hline TEI & & & & & 146 & 0 & 0 & 0 & 0 & 0 & 0 & 0 & & & & & & 146 & 100 & 0 & 0 \\
\hline${ }^{\mathrm{b}} \mathbf{S Y N}$ & & & & & 9 & 5 & 28 & $63 \mid$ & 5 & 1 & 1 & 0 & & & & & & 105 & 93.7 & 7 & 6.3 \\
\hline DAP & & & & 5 & 4 & 23 & 48 & 58 & 8 & 0 & 0 & & & & & & & 146 & 100 & 0 & 0 \\
\hline LZD & & & & & 1 & 9 & 118 & 16 & 2 & 0 & 0 & 0 & 0 & & & & & 144 & 98.6 & 2 & 1.4 \\
\hline CHL & & & & & & & & 13 & 101 & 20 & 6 & 5 & 1 & 0 & & & & 140 & 95.9 & 6 & 4.1 \\
\hline
\end{tabular}

${ }^{a}$ Antimicrobial: AMP Ampicillin, GEN Gentamicin, ERY Erythromycin, TET Tetracycline, TGC Tigecylince, CIP Ciprofloxacin, VAN Vancomicin, TEI Teicoplanin, SYN Quinupristin-dalfopristin, DAP Daptomycin, LZD Linezolid, CHL Chloramphenicol

${ }^{b}$ SYN: Enterococcus faecalis was excluded of quinupristin-dalfopristin MIC distribution, WT and NWT phenotypes due to its intrinsic resistance

from 0 (worst scenario) to 100 (best scenario). Each question has a fixed score. Internal and external biosecurity scores are determined by the weighted average of the subcategories, as it was established by Laanen et al. [22]. Total biosecurity score is the result of the average of internal and external biosecurity scores.

The questionnaire was translated from English into Spanish and the questions were answered using an online platform [24] by the manager of the pig farm. Results were transcribed to the Biocheck.Ugent ${ }^{\mathrm{Tm}}$ online database and an Excel sheet (Microsoft Office). The final scores for each biosecurity category were obtained for each farm and were used for further analyses.

The particular characteristics of the organic-extensive herds, their management and their husbandry practices did not conform to most of the Biocheck.Ugent ${ }^{\mathrm{Tm}}$ sections and we failed to include the biosecurity scores of these herds. For this reason, biosecurity analyses were restricted to intensive herds.

\section{Statistical analysis}

\section{Mixed-effects logistic regressions}

A database including farm characteristics, AMU (i.e. total values and specific consumptions for each antimicrobial class), biosecurity scores and AMR phenotypic data was created in an Excel sheet (Microsoft Office). The database was introduced into $R$ version 3.6.2 [25] where all statistical analyses were conducted.

As a first step, descriptive analyses were performed to identify low variability in AMR. Thus, for those antimicrobials that had less than $5 \%$ of isolates classified as WT or NWT no further analyses were carried out due to lack of variability [26]. Quantitative variables were transformed to a $\log _{10}$ scale. Production system (intensive/organic-extensive), sample type (faeces/slurry/environmental), total AMU and AMU divided by antimicrobial classes were included as independent variables in a mixed-effects logistic regression to evaluate their influence in the occurrence of NWT, MDR and PNS phenotypes for the antimicrobials evaluated. Farm was introduced in the model as a random effect. For intensive farms, biosecurity scores were included as independent variables. Quinupristin-dalfopristin was excluded for the characterization of MDR and PNS phenotypes in E. faecalis due to its intrinsic resistance [27].

In each model, all variables were initially tested using an univariate mixed-effects logistic regression using the package lme4 [28]. Predictor variables with $p \leq 0.10$ in the likelihood ratio test (LRT) were considered for inclusion in subsequent multivariate analysis. In the multivariate analysis, all the combinations of fixed effects selected from the univariate analyses were run and ranked by the Akaike information criterion (AIC) using dredge function from $M u M I n$ package [29]. The statistical models with $\triangle \mathrm{AIC} \leq 2$ were individually analyzed and a model with $p \leq 0.05$ in the LRT for each independent variable with a variance inflation factor $\leq 3.3$ was selected as final model. Results for the fixed effects were reported as odds ratio (OR) including its 95\% confidence interval $(95 \% \mathrm{CI})$.

\section{Clustering of AMR patterns}

A clustering of AMR patterns was performed for $E$. coli and Enterococcus spp. isolates. Taking into account the chemical structure of the antimicrobials tested, an isolate was considered microbiologically resistant to an 
antimicrobial class if it was resistant to at least one member of such class. For both bacterial genera, isolates were clustered according to their AMR pattern using the unweighted pair group method with arithmetic mean (UPGMA) as hierarchical clustering method. Enterococcus isolates were divided in E. faecalis and enterococci other than E. faecalis, excluding the streptogramins antimicrobial class in E. faecalis clustering due to its intrinsic resistance to quinupristindalfopristin. The pheatmap package [30] was used for the representation of the clustered heatmaps of isolates. The AMR comparison between isolates from the two main clusters was carried out with the Chi-Square test.

\section{Association between AMU and biosecurity}

The association between AMU and biosecurity scores on intensive swine farms was initially tested with the pairwise Spearman's rank correlation. Correlations were removed if $p>0.05$, adjusting this $p$-value to avoid false positives using the Benjamini \& Hochberg method [31]. The correlations were carried out with the Hmisc package [32]. Biosecurity scores were afterwards included as independent variables in a generalized gamma regression to evaluate their influence in the total AMU following the methods described in the mixed-effects logistic regression.

\section{Principal component analysis}

For the evaluation of the biosecurity on intensive swine farms, a principal component analysis (PCA) was performed on the biosecurity subcategories and the two main dimensions for the principal components were characterized. Farms were clustered by their biosecurity practices using the UPGMA as hierarchical clustering method. Biosecurity scores, number of fattening pigs per feedlot, total AMU and AMU divided by antimicrobial classes for each cluster were compared by Wilcoxon signed rank test.

\section{Results}

\section{Escherichia coli antimicrobial resistance}

A total of 148 isolates were recovered from faeces, slurry and environmental samples from 37 farms, with four isolates per herd. The MICs for these E. coli isolates are shown in Table 1. While 108 isolates (73.0\%) were resistant to at least one antimicrobial, with 78 isolates (52.7\%) defined as MDR, 40 isolates (27.0\%) were characterized as PNS. There were 25 MDR patterns, being the most common the combination of penicillins, tetracyclines, sulfonamides, diaminopyrimidines and phenicols (28.2\%), followed by the combination of penicillins, tetracyclines, sulfonamides and diaminopyrimidines (20.5\%). NWT phenotype was mainly detected for tetracycline (64.9\%) and ampicillin (55.4\%), followed by sulfamethoxazole (50.7\%) and trimethoprim (48.6\%). Less frequent were the resistances to chloramphenicol (29.7\%), ciprofloxacin (16.2\%) or nalidixic acid (9.5\%). Only one E. coli isolate exhibited AMR to extendedspectrum beta-lactamases by its lack of susceptibility to ampicillin, cefotaxime and ceftazidime. All isolates were susceptible to meropenem, tigecycline or colistin. As shown in Fig. 1a, AMR clustering of E. coli categorizes the isolates into two main clusters, mainly determined by the resistance to sulfonamides and diaminopyrimidines $(p<0.001)$. Most of the isolates resistant to sulfonamides, diaminopyrimidines, quinolones and phenicols were recovered from intensive farms.

When investigating the factors associated with the AMR to the antimicrobials evaluated, as MDR and PNS phenotypes, the only factor identified was the production system. NWT phenotype was less frequent in isolates from organic-extensive farms for ampicillin $(p<$ $0.001 ; \mathrm{OR}=0.15 ; 95 \% \mathrm{CI}=0.05-0.36)$, tetracycline $(p<$ 0.001; $\mathrm{OR}=0.06 ; 95 \% \mathrm{CI}=0.01-0.19)$, ciprofloxacin $(p<$ 0.01 ; $\mathrm{OR}=0.07 ; 95 \% \mathrm{CI}<0.01-0.38)$, nalidixic acid $(p<$ $0.05 ; \mathrm{OR}=0.05 ; 95 \% \mathrm{CI}<0.01-0.67)$, sulfamethoxazole $(p<0.001 ; \mathrm{OR}=0.16 ; 95 \% \mathrm{CI}=0.05-0.40)$, trimethoprim $(p<0.001 ; \mathrm{OR}=0.18 ; 95 \% \mathrm{CI}=0.06-0.43)$ and chloramphenicol $(p<0.001$; OR $=0.01 ; 95 \% \mathrm{CI}=0.01-0.19)$, as it was the MDR $(p<0.001 ; \mathrm{OR}=0.13 ; 95 \% \mathrm{CI}=0.04-0.33)$ phenotype. PNS isolates were also more frequent in these organic-extensive herds $(p<0.001$; OR $=5.61 ; 95 \%$ $\mathrm{CI}=2.91-12.17)$. No associations were observed for the antibiotic gentamicin.

In the $72 \mathrm{E}$. coli isolated on intensive farms, the factors associated with the AMR revealed that ciprofloxacin resistance was associated with high phenicols consumption $(p<0.05 ;$ OR $=6.30 ; 95 \%$ CI: $1.04-80.40)$, while chloramphenicol resistance was linked to a high quinolone consumption $(p<0.05$; OR $=5.38$; 95\% CI: $1.02-46.13)$. An increase in the biosecurity score for feed, water and equipment supply was slightly associated with a lower gentamicin resistance $(p<0.05$; OR $=0.91$; 95\% CI: 0.78 $0.98)$, as it was observed for cleaning and disinfection with sulfamethoxazole resistance $(p<0.01 ; \mathrm{OR}=0.96$; 95\% CI: 0.92-0.99) and the MDR pattern $(p<0.05$; OR $=$ 0.97; 95\% CI: 0.93-0.99). Tetracycline resistance was slightly associated with a better disease management $(p<0.05 ;$ OR $=1.04 ; 95 \%$ CI: $1.00-1.11)$. No associations were observed for ampicillin, trimethoprim or nalidixic acid, as the PNS phenotype.

\section{Enterococcus spp. antimicrobial resistance}

A total of 146 Enterococcus spp. isolates from faeces, slurry and environmental samples were further typed and tested for antimicrobial resistance. In these isolates, the predominant species were E. faecium (105) and $E$. 
a)

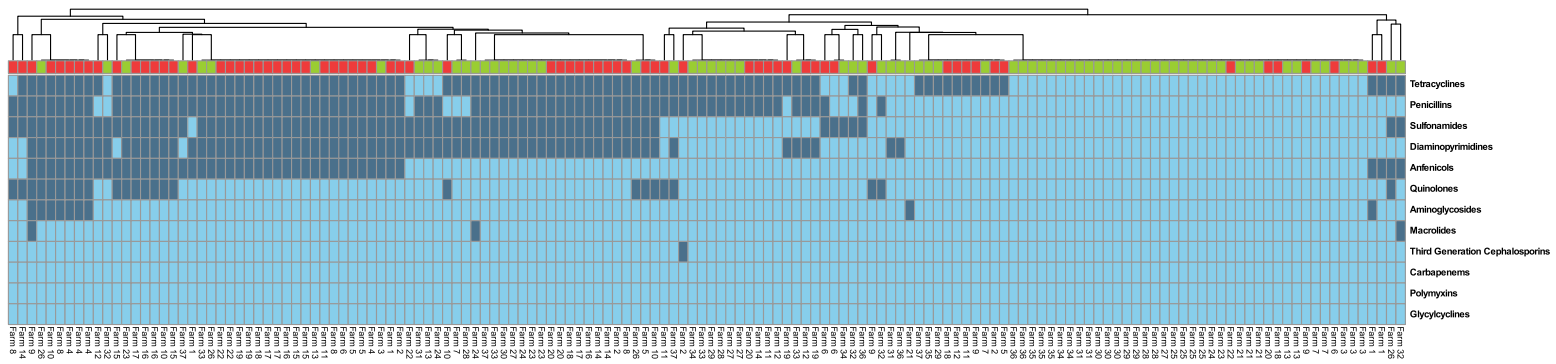

b)

c)
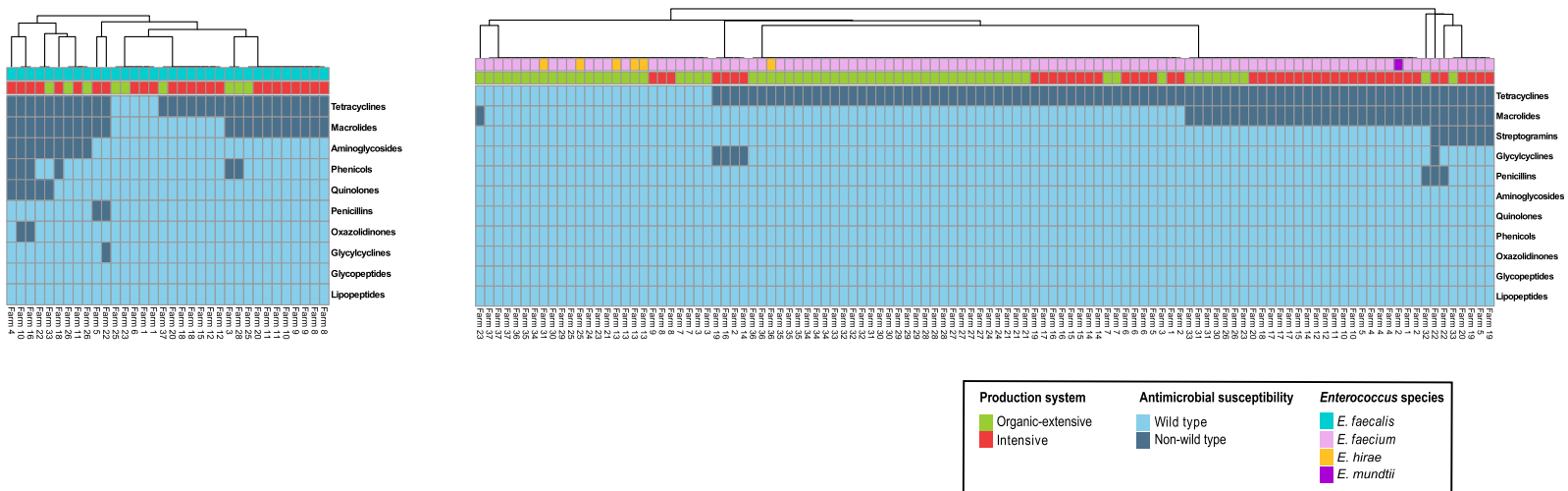

Fig. 1 Antimicrobial resistance pattern in a Escherichia coli (148), b Enterococcus faecalis (34) and c enterococci other than E. faecalis (112) recovered from 37 Spanish pig farms. The isolates were clustered according to their antimicrobial resistance pattern using the unweighted pair group method with arithmetic mean (UPGMA) as hierarchical clustering method. For this purpose, the pheatmap package (Kolde, 2019) was used. Streptogramins antimicrobial class was excluded from the E. faecalis clustering due to its intrinsic resistance

faecalis (34), being less frequent E. hirae (6) and E. mundtii (1).

The MICs of these isolates are shown in Table 2. Twenty-seven isolates (18.5\%) were defined as PNS, while $119(81.5 \%)$ exhibited resistance to at least one antimicrobial, with 21 isolates (14.4\%) characterized as MDR. The tetracyclines, macrolides and streptogramins MDR combination was the most frequent (23.8\%) among the 11 MDR patterns observed. The NWT phenotype was predominant for tetracycline (78.8\%), followed at a distance by erythromycin (39.0\%). Less frequent was any observation of resistance to gentamicin (6.2\%), tigecycline (4.1\%), chloramphenicol (4.1\%), ciprofloxacin (3.4\%), ampicillin (3.4\%) and linezolid (1.4\%). In enterococci other than $E$. faecalis, quinupristindalfopristin resistance was uncommon (6.3\%). All isolates were susceptible to daptomycin, vancomycin and teicoplanin. In E. faecalis and enterococci other than $E$. faecalis two main clusters were appreciated when grouping isolates by their AMR pattern whether they had or not a MDR phenotype (Fig. 1b and Fig. 1c).

The factors significantly associated with AMR to tetracycline, erythromycin and quinupristin-dalfopristin, as
MDR and PNS patterns are shown in Table 3. PNS phenotype was more frequent on organic-extensive farms $(p<0.001)$. Tetracycline NWT phenotype was less common in organic-extensive herds $(p<0.001)$. Erythromycin resistance was more frequent in Enterococcus recovered from slurry samples $(p<0.05)$ and it was associated with a higher lincosamides $(p<0.01)$, penicillins $(p<0.01)$ and phenicols $(p<0.01)$ usage. The MDR phenotype was also more common in herds with high lincosamides $(p<0.001)$ and phenicols $(p<0.01)$ use. Quinupristin-dalfopristin NWT phenotype in enterococci other than E. faecalis was linked to farms with high lincosamides use $(p<0.001)$. No associations were observed for the antibiotic gentamicin.

When characterizing the factors associated with the AMR of the 71 Enterococcus isolates recovered on intensive farms it revealed that the NWT phenotype was consistently high on farms with high lincosamides consumption for quinupristin-dalfopristin resistance $(p<0.01 ; \mathrm{OR}=5.96 ; 95 \% \mathrm{CI}=1.94-423.51)$, as it was the MDR phenotype $(p<0.05 ; \mathrm{OR}=2.61 ; 95 \% \mathrm{CI}=1.27-$ 7.62). An increase in the biosecurity score for disease management was associated with a slightly higher 
Table 3 Factors associated with the non-wild type (NWT) phenotype for erythromycin, tetracycline, quinupristin-dalfopristin, multidrug-resistance and pansusceptible profile in 146 Enterococcus isolates recovered from 37 Spanish pig farms

\begin{tabular}{|c|c|c|c|c|c|c|}
\hline \multirow{2}{*}{ Independent variable } & & \multicolumn{5}{|l|}{${ }^{\mathrm{a}}$ Antimicrobial } \\
\hline & & $\begin{array}{l}\text { ERY } \\
\text { OR }(95 \% \text { Cl) }\end{array}$ & $\begin{array}{l}\text { TET } \\
\text { OR }(95 \% \mathrm{Cl})\end{array}$ & $\begin{array}{l}\text { 'SYN } \\
\text { OR }(95 \% \mathrm{Cl})\end{array}$ & $\begin{array}{l}{ }^{d} M D R \\
\text { OR }(95 \% \mathrm{Cl})\end{array}$ & $\begin{array}{l}\text { dPNS } \\
\text { OR }(95 \% \mathrm{Cl})\end{array}$ \\
\hline \multirow{3}{*}{ Management system } & & & & & & \\
\hline & Intensive (Ref. category) & ${ }^{b} \mathrm{NI}$ & & ${ }^{b} \mathrm{NI}$ & ${ }^{b} \mathrm{Nl}$ & \\
\hline & Organic-extensive & & $0.11(0.02-0.35)$ & & & $9.47(2.66-59.26)$ \\
\hline \multirow[t]{3}{*}{ Type of sample } & Faeces (Ref. category) & & ${ }^{b} \mathrm{NI}$ & ${ }^{b} \mathrm{NI}$ & ${ }^{b} \mathrm{NI}$ & ${ }^{b} \mathrm{NI}$ \\
\hline & Slurry & $6.63(1.66-35.00)$ & & & & \\
\hline & Environment & $1.83(0.66-5.71)$ & & & & \\
\hline \multirow[t]{3}{*}{ Antimicrobial consumption } & Lincosamides & $2.88(1.45-6.63)$ & ${ }^{b} \mathrm{NI}$ & $10.98(3.00-1577.32)$ & $3.79(2.05-9.80)$ & ${ }^{\mathrm{b}} \mathrm{NI}$ \\
\hline & Phenicols & $7.57(1.78-62.24)$ & ${ }^{b} \mathrm{NI}$ & ${ }^{b} \mathrm{NI}$ & $6.99(1.57-47.16)$ & ${ }^{\mathrm{b}} \mathrm{NI}$ \\
\hline & Penicillins & $2.79(1.34-6.94)$ & ${ }^{b} \mathrm{NI}$ & ${ }^{b} \mathrm{NI}$ & ${ }^{b} \mathrm{Nl}$ & ${ }^{\mathrm{b}} \mathrm{NI}$ \\
\hline
\end{tabular}

${ }^{a}$ Antimicrobial: ERY Erythromycin, TET Tetracycline, SYN Quinupristin-dalfopristin, MDR Multidrug-resistance, PNS Pansusceptibility

${ }^{\mathrm{b}} \mathrm{NI}$ : not included in the final model

'SYN: E. faecalis was excluded of the quinupristin-dalfopristin mixed-effects logistic regressions

${ }^{d}$ MDR; ${ }^{d}$ PNS: quinupristin-dalfopristin was excluded for the characterization of MDR and PNS phenotypes in $E$. faecalis

resistance for erythromycin $(p<0.05 ; \mathrm{OR}=1.04 ; 95 \%$ $\mathrm{CI}=1.01-1.09)$ and tetracycline $(p<0.05 ; \mathrm{OR}=1.05$; $95 \% \mathrm{CI}=1.01-1.18)$, together with a lower PNS $(p<$ $0.05 ; \mathrm{OR}=0.95 ; 95 \% \mathrm{CI}=0.85-0.99$ ). No associations were observed for gentamicin.

\section{Biosecurity scores on intensive swine farms}

The results of the biosecurity questionnaires for 18 intensive farms are presented in Table 4 and Fig. 2a. Within these herds, two types of swine farms were included in the study: 12 finishing and six farrow-tofinish farms. The farm mean biosecurity score was $69.2 \pm 10.1$. External biosecurity was higher $(73.7 \pm 9.5)$ than internal biosecurity $(64.6 \pm 13.6)$. The highest internal biosecurity score was achieved in disease management $(80.0 \pm 21.7)$, while parameters referring to the measures between compartments, working lines and use of equipment obtained the lowest score $(45.7 \pm 20.0)$, with one farm scoring 0 in this subcategory. Among the external biosecurity parameters, the highest score was

Table 4 Biosecurity scores (Biocheck.UGent ${ }^{\mathrm{TM}}$ ) for the different categories of internal and external biosecurity on 18 intensive Spanish swine farms

\begin{tabular}{|c|c|c|c|c|c|c|}
\hline & & Mean & SD & Median & Min & Max \\
\hline \multirow[t]{7}{*}{${ }^{\mathrm{a}}$ Internal biosecurity score } & & 64.6 & 13.6 & 66 & 40 & 86 \\
\hline & Disease management & 80.0 & 21.7 & 80.0 & 20 & 100 \\
\hline & ${ }^{\mathrm{C}}$ Farrowing and suckling period & 64.2 & 12.1 & 64.0 & 50 & 86 \\
\hline & ${ }^{\mathrm{C}}$ Nursery unit & 58.4 & 11.5 & 50.0 & 50 & 71 \\
\hline & Fattening unit & 72.6 & 21.0 & 79.0 & 21 & 100 \\
\hline & Measures between compartments and the use of equipment & 45.7 & 20.0 & 46.5 & 0 & 71 \\
\hline & Cleaning and disinfection & 74.7 & 21.5 & 75.0 & 40 & 100 \\
\hline \multirow[t]{7}{*}{${ }^{\mathrm{a}}$ External biosecurity score } & & 73.7 & 9.5 & 74.0 & 60 & 98 \\
\hline & Purchase of animals and semen & 91.7 & 9.5 & 96 & 68 & 100 \\
\hline & Transport of animals, removal of manure and dead of animals & 80.2 & 11.4 & 79.0 & 59 & 100 \\
\hline & Feed, water and equipment supply & 56.3 & 17.8 & 53.0 & 30 & 100 \\
\hline & Personnel and visitors & 63.1 & 21.7 & 59.0 & 29 & 100 \\
\hline & Vermin and bird control & 72.8 & 27.2 & 80.0 & 10 & 100 \\
\hline & Environment and region & 57.2 & 28.9 & 65.0 & 0 & 100 \\
\hline${ }^{\mathrm{b}}$ Total biosecurity score & & 69.2 & 10.1 & 67.5 & 53 & 92 \\
\hline
\end{tabular}

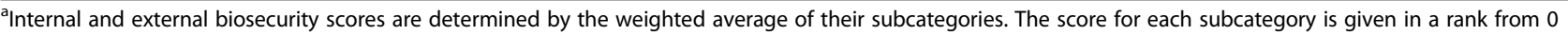
(worst scenario) to 100 (best scenario)

${ }^{\mathrm{b}}$ Total biosecurity score is the result of the average of internal and external biosecurity scores

'Only six farrow-to-finish intensive farms were included in the study 
a)

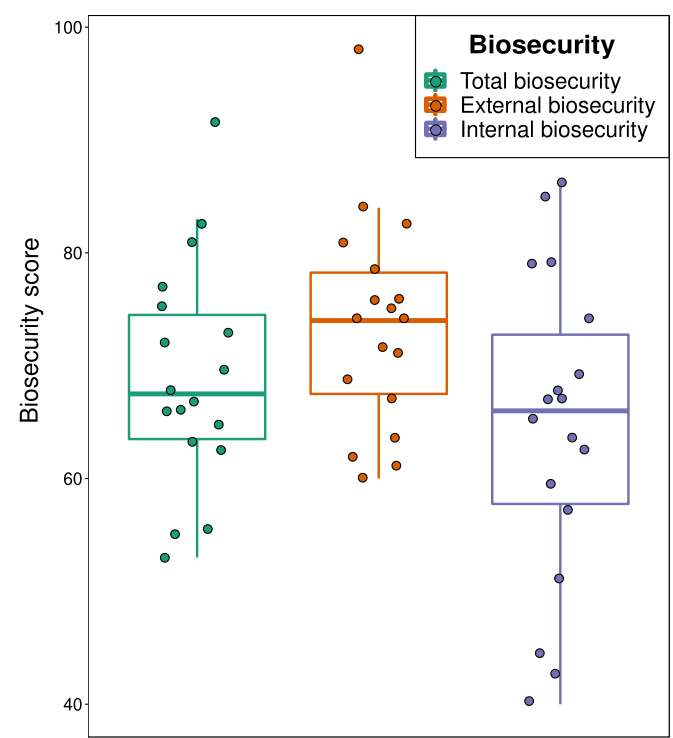

c)

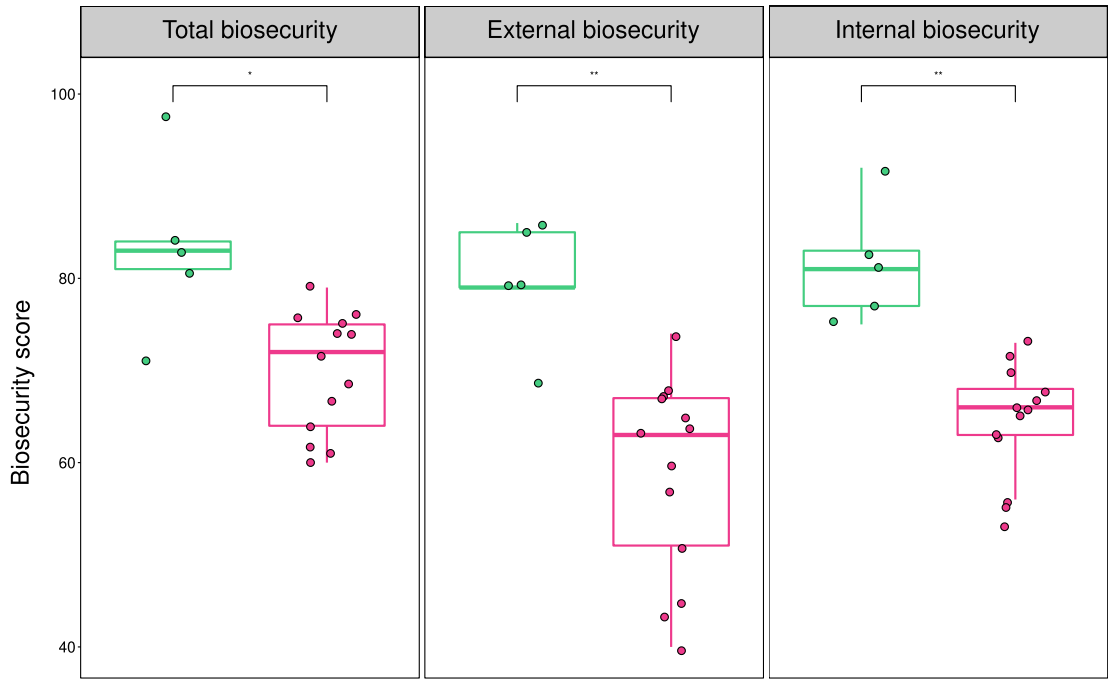

\section{Farm clusters \\ - Cluster A \\ Cluster B}

b)

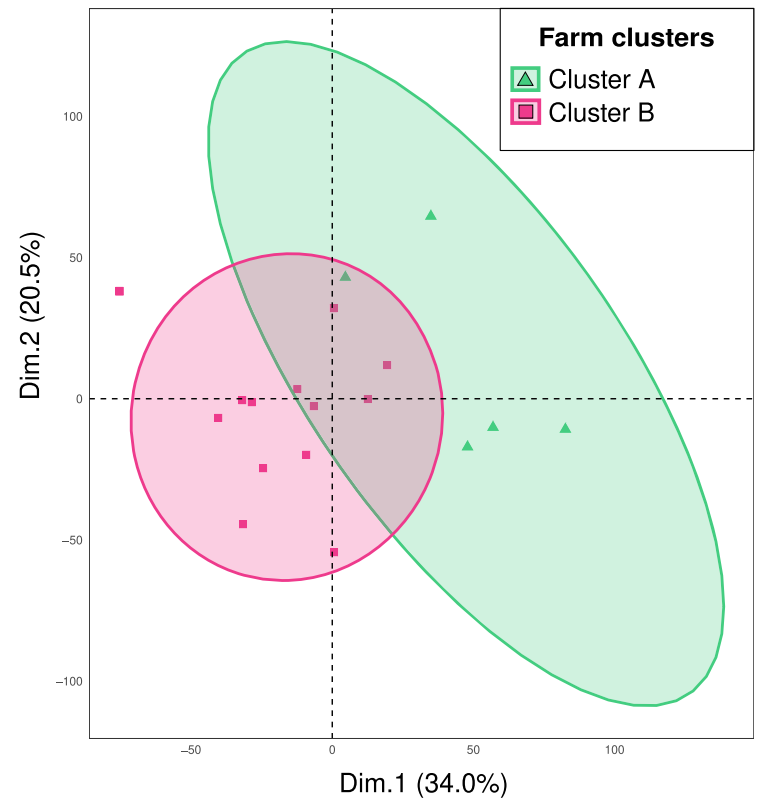

d)

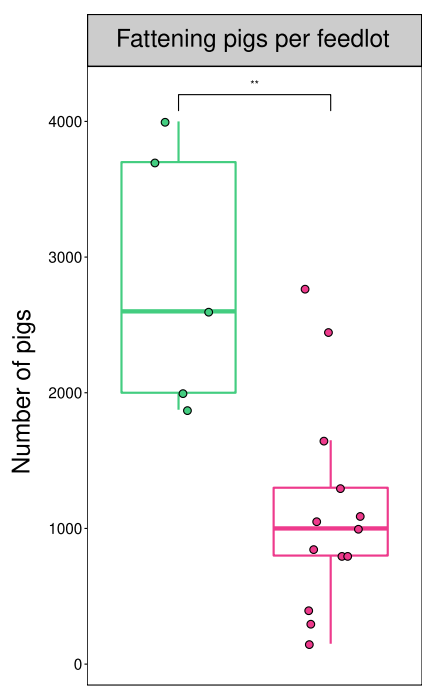

Fig. 2 Biosecurity characterization of 18 intensive Spanish pig farms. a Boxplots of the total, external and internal biosecurity scores per farm. b Principal component analysis followed by an UPGMA hierarchical clustering analysis for grouping farms according to their scores in external and internal biosecurity practices. C) Boxplots of total, internal and external biosecurity scores within each farm cluster. D) Boxplot of the number of fattening pigs per feedlot within each farm cluster. Each farm is represented by a dot with horizontal jitter for visibility. The horizontal box lines represent the first quartile, the median, and the third quartile. Whiskers include the range of points within the 1.5 interquartile range. The differences per cluster were evaluated with the Wilcoxon signed-rank test 
obtained in the purchase of breeding pigs, piglets and semen (91.7 \pm 9.5$)$, being feed, water and equipment supply practices the lowest rated ( $56.3 \pm 17.8)$.

No significant associations were observed between AMU and the biosecurity scores. When ordinating the farms based on their biosecurity practices, the first two dimensions of the PCA represented the $54.5 \%$ of the variability (Fig. 2b). Dimension 1 represented the 34.0\% of the variability and it was mainly determined by the vermin and bird control external subcategory (23.7\%). Dimension 2 included the $20.5 \%$ of the variability and it was predominantly determined by the environment and region external subcategory $(63.1 \%)$, which refers to the farm location. Based on the farm similarities in biosecurity practices, two clusters of farms were identified: cluster A (5 farms) and cluster B (13 farms) (Fig. 2b). The total, external and internal biosecurity scores in cluster A were significantly higher $(p<0.05)$ than in cluster B (Fig. 2c). The number of fattening pigs per feedlot was significantly higher $(p<0.01)$ on farms with higher biosecurity (cluster A) (Fig. 2d).

\section{Discussion}

A direct transmission of AMR bacteria has been described from pigs and their related farm environment to humans, soil or water [33]. Current policies aim at reducing AMU and we need efficient targets to measure accurately the impact of such interventions. Commensal bacteria, such as Escherichia coli or Enterococcus spp., are important AMR reservoirs [34] and their use as sentinel microorganisms help to understand time-trends in AMR surveillance $[35,36]$. These aspects make these bacteria an excellent tool to evaluate the effect of different on-farm interventions in the AMR threat.

In our study, the main factor that contributed to explain the AMR differences in these bioindicators was the production system. Thus, the chance to find PNS commensal E. coli and Enterococcus isolates was more than five times higher on organic-extensive than intensive farms. These findings were consistent with the study carried out by Österberg et al. [13], suggesting a lower AMR in commensal E. coli recovered from organic pig herds when compared to conventional farming. Since a clear association between AMR and AMU trends in both microorganisms has been previously described [37-39], the most likely explanation for these resistance differences between production systems seems to be the low AMU on organic-extensive farms. Differences in husbandry, such as lower animal density and other risk factors associated with confinement [40], a longer lifespan with less growth pressure, usually slaughter after 14 months of age and a wider behavioral repertoire, which reduces their stress and improves animal welfare, are factors behind this lower AMU.
However, the emergence and spread of AMR bacteria is more complex than a direct antimicrobial selective pressure [13]. In this context, high phenicols use was associated with an increase of six times in ciprofloxacin resistance in commensal E. coli recovered from intensive herds, while quinolones use increased the risk of chloramphenicol resistance in these isolates also in nearly six times. This last finding has been previously reported by Murray et al. [41], since ciprofloxacin has been demonstrated to increase relative abundance of chloramphenicol antimicrobial resistance genes (ARGs) in Enterobacteriacae. In enterococci, this association between AMR and AMU was revealed mainly by lincosamides use, with an increase in the AMR of nearly two times for erythromycin, 11 times for quinupristindalfopristin and four times for the MDR, which was consistent on intensive farms for the last two resistance phenotypes. Cross-resistance among lincosamides, macrolides and streptogramins is common due to erm ARGs [42]. In fact, an increased resistance in enterococci to these antimicrobials has been associated with in-feed use of tylosin, a macrolide, and virginiamycin, a streptogramin [43]. Erythromycin resistance in commensal Enterococcus was also higher on slurry samples and farms with high penicillins and phenicols consumption. Altogether could be explained by a common oral administration of these compounds [44], which might contribute to the antimicrobial contamination of slurry, and hence, an increase in AMR.

Interestingly, while all $E$. coli were susceptible to last resort antimicrobials forbidden in food-producing animals, such as meropenem or tigecycline, [45], Enterococcus resistant to compounds as tigecycline or linezolid were isolated on intensive farms. Tigecycline resistance in enterococci has been associated with certain tetracycline ARGs, as tet $(L)$ or tet $(M)$, while linezolid resistance is determined by ARGs that also confer resistance to phenicols, such as the cfr-like ARGs, and not only to phenicols, but also to lincosamides, pleuromutilins and streptogramin A, such as the optrA ARG [46]. These facts evidenced that cross-resistance to antimicrobials not approved on swine farms can also occur.

Another factor that has been reported as beneficial for AMR control is the application of high standards of biosecurity, mainly by its assistance to reduce AMU to treat bacterial diseases [12]. The biosecurity measures carried out on the intensive farms included in our study were similar to those reported in other European swine herds [5, 23], with a higher internal biosecurity, particularly in the cleaning and disinfection subcategory. Despite high biosecurity has been associated with a reduced AMU [47], no associations were appreciated within our farms, as it was also revealed in a Swedish risk factor study on pig farms [48]. The relationship between biosecurity and 
AMU seems to be complex. High AMU may lead to an increase in biosecurity standards, while poor biosecurity may be linked to an increased need for antimicrobial treatments. In addition, both AMU and biosecurity are influenced by factors that may act as confounders [49, 50] and thus limit the association between both factors. The only difference observed was that larger herds, determined by the number of fattening pigs per feedlot, had implemented better biosecurity measures when compared with smaller farms, as it has been previously reported [22].

Among the biosecurity measures applied on these farms, a higher cleaning and disinfection score was associated with a slightly lower resistance to sulfamethoxazole and the MDR phenotype in commensal E. coli, suggesting that a robust cleaning and disinfection might support AMR mitigation. A correct procedure in these protocols can lead to a reduction in the transmission of bacterial pathogens, as it has been previously described for instance in Salmonella spp. removal [51, 52] and, hence, in the AMU. Besides, a higher control of feed, water and equipment supply was associated with a lower gentamicin resistance, as it is recognized that animal feed and water can be a source of AMR bacteria, as $E$. coli or Salmonella [53]. In contrast, we observed that a better disease management was associated with a slightly lower PNS and a higher resistance for erythromycin in Enterococcus spp., and for tetracycline in both bioindicators. Positive associations between biosecurity and AMR may be linked in some farms to improvements of biosecurity associated to prior health problems and thus to AMU. However, this finding suggests that despite rigorous biosecurity and hygiene measures appear to have important roles in the control and spread of AMR, beyond the prudent and rational AMU, data on AMR control are sparse, and further investigations need to be performed.

\section{Conclusions}

This study proposes that commensal Escherichia coli and Enterococcus spp. could be considered adequate onfarm bioindicators for the evaluation of factors that contribute to the AMR development. Within these bacteria, AMR was influenced by the production system, with antimicrobial usage as the main differential factor, as it was appreciated for enterococci on farms with high lincosamides usage. Although we did not observe a direct relationship between AMU and biosecurity scores on intensive farms, particular measures, such as adequate cleaning and disinfection protocols, seemed to have an impact in AMR development. However, further investigations need to be implemented for the evaluation of the effect of biosecurity aspects in the AMR threat.

\section{Abbreviations}

AIC: Akaike information criterion; AMR: Antimicrobial resistance;

AMU: Antimicrobial use; ARG: Antimicrobial resistance gene; $\mathrm{BHI}$ : Brain heart infusion; ECOFF: Epidemiological cut-off value; ESVAC: European Surveillance of Veterinary Antimicrobial Consumption; EUCAST: European Committee on Antimicrobial Susceptibility Testing; LRT: Likelihood ratio test;

MDR: Multidrug-resistance; MIC: Minimum inhibitory concentration; NWT: Non-wild type; OR: Odds ratio; PCA: Principal component analysis; PNS: Pansusceptibility; UPGMA: Unweighted pair group method with arithmetic mean; WT: Wild type; $95 \%$ Cl: $95 \%$ confidence interval

\section{Acknowledgments \\ We acknowledge the excellent technical assistance provided by Diana Molina and the contribution in some parts of the research by Sandra González from Aquilón CyL S.L. We would like to thank also the veterinary practitioners and farmers willingness, and in particular Álvaro Fernández- Blanco for his support on contacting the farms.}

\section{Authors' contributions}

Study design was performed by AC, PR and AAO. Bacterial isolation and characterization was performed by OMA, MGG and HP. OMA performed the antimicrobial susceptibility testing. Statistical analyses were performed by OMA with contribution from EGM and AC. HA, AC, AAO and EGM provided technical and scientific support on the analysis. OMA, HA, AC, AAO, and EGM participated in the manuscript writing or contributed to its revision. All authors revised the manuscript and approved the final version. The authors read and approved the final manuscript.

\section{Funding}

The research was funded by an INIA project (RTA2015-00075-c04-03). Oscar Mencía-Ares and Héctor Puente hold a grant from the Spanish Government (Ministerio de Educación y Formación Profesional) FPU 16/03485 and FPU 17/00466. Manuel Gómez-García hold a grant from Junta de Castilla y León co-financed by the European Social Fund (LE131-18). Hector Argüello is financially supported by the "Beatriz Galindo" Programme from the Spanish Government (Ministerio de Educación y Formación Profesional) BEAGAL-18106. Research in the laboratory of Avelino Alvarez-Ordóñez is funded by the European Commission under European Union's Horizon 2020 research and innovation program under grant agreement No 818368 and the Ministry of Science and Innovation of the Spanish Government (AGL2016-78085-P).

Availability of data and materials

Not applicable.

\section{Declarations}

Ethics approval and consent to participate Not applicable.

Consent for publication

Not applicable.

\section{Competing interests}

The authors declare that they have no competing interests.

\section{Author details}

${ }^{1}$ Department of Animal Health, Faculty of Veterinary, Universidad de León, León, Spain. ${ }^{2}$ Animal and Grassland Research and Innovation Centre, Teagasc, Moorepark, Fermoy, Ireland. '3School of Veterinary Medicine, University College Dublin, Dublin, Ireland. ${ }^{4}$ Department of Food Hygiene and Technology, Faculty of Veterinary, Universidad de León, León, Spain. ${ }^{5}$ Institute of Food Science and Technology, Universidad de León, León, Spain.

Received: 17 December 2020 Accepted: 11 March 2021

Published online: 19 March 2021

\section{References}

1. WHO. Antibiotic resistance. 2018. https://www.who.int/news-room/factsheets/detail/antibiotic-resistance. Accessed 8 Nov 2020. 
2. CDC. Antibiotic resistance threats in the United States, 2013. Atlanta; 2013. https://www.cdc.gov/drugresistance/pdf/ar-threats-2013-508.pdf. Accessed 16 Jun 2020

3. Booton RD, Meeyai A, Alhusein $N$, Buller $H$, Feil E, Lambert $H$, Mongkolsuk S, Pitchforth E, Reyher KK, Sakcamduang W, Satayavivad J, Singer AC, Sringernyuang $L$, Thamlikitkul V, Vass $L$, Avison MB, Turner KME, Avison MB, Alhusein N, Booton RD, Buller $H$, Chantong B, Charoenlap N, Couto N, Dulyayangkul P, Feil E, Gibbon MJ, Gould VC, Lambert H, Meeyai A, Mongkolsuk S, Montrivade V, Pitchforth E, Phoonsawad K, Rangkadilok N, Ratanakorn P, Reyher KK, Sakcamduang W, Satayavivad J, Singer AC, Sirikanchana K, Sringernyuang L, Suriyo T, Suwanpakdee S, Thamlikitkul V, Turner KME, Vass L, Wichuwaranan K, Wiratsudakul $\mathrm{A}$, et al. One health drivers of antibacterial resistance: quantifying the relative impacts of human, animal and environmental use and transmission. One Heal. 2021;12:100220. https://doi.org/10.11 01/2020.06.09.20126433.

4. Ma F, Xu S, Tang Z, Li Z, Zhang L. Use of antimicrobials in food animals and impact of transmission of antimicrobial resistance on humans. Biosaf Heal. 2020;3(1):32-8. https://doi.org/10.1016/j.bsheal.2020.09.004.

5. Raasch S, Postma M, Dewulf J, Stärk KDC, Grosse Beilage E. Association between antimicrobial usage, biosecurity measures as well as farm performance in German farrow-to-finish farms. Porc Heal Manag. 2018;4:30. https://doi.org/10.1186/s40813-018-0106-5.

6. EMA, EFSA. EMA and EFSA joint scientific opinion on measures to reduce the need to use antimicrobial agents in animal husbandry in the European Union, and the resulting impacts on food safety (RONAFA). EFSA J. 2017; 15(1):1-245. https://doi.org/10.2903/j.efsa.2017.4666.

7. AEMPS. Informe JIACRA España. Primer análisis del integrado del consumo de antibióticos y su relación con la aparición de resistencia. Madrid ; 2018. https://www.resistenciaantibioticos.es/es/system/files/field/files/informe_jia cra-espana. pdf?file=1\&type=node\&id=410\&force=0. Accessed 29 Apr 2020 .

8. UK-VARSS. UK Veterinary Antibiotic Resistance and Sales Surveillance Report (UK-VARSS 2019). New haw, Addlestone; 2020. https://assets.publishing. service.gov.uk/government/uploads/system/uploads/attachment_data/file/ 950126/UK-VARSS_2019_Report_2020-TPaccessible.pdf. Accessed 29 Apr 2020.

9. European Commission. 2013/652/EU: commission implementing decision of 12 November 2013 on the monitoring and reporting of antimicrobial resistance in zoonotic and commensal bacteria (notified under document C (2013) 7145). Off J Eur Union 2013;303:26-39. https://eur-lex.europa.eu/legalcontent/en/TXT/?uri=CELEX\%3A32013D0652. Accessed 14 May 2020

10. EFSA, Aerts M, Battisti A, Hendriksen R, Kempf I, Teale C, et al. Technical specifications on harmonised monitoring of antimicrobial resistance in zoonotic and indicator bacteria from food-producing animals and food. EFSA J. 2019;17:5709. https://doi.org/10.2903/j.efsa.2019.5709.

11. Postma M, Stärk KDC, Sjölund M, Backhans A, Beilage EG, Lösken S, Belloc C, Collineau L, Iten D, Visschers V, Nielsen EO, Dewulf J, MINAPIG consortium, et al. Alternatives to the use of antimicrobial agents in pig production: a multi-country expert-ranking of perceived effectiveness, feasibility and return on investment. Prev Vet Med. 2015;118(4):457-66. https://doi.org/10.1 016/J.PREVETMED.2015.01.010.

12. Davies $R$, Wales $A$. Antimicrobial resistance on farms: a review including biosecurity and the potential role of disinfectants in resistance selection. Compr Rev Food Sci Food Saf. 2019;18(3):753-74. https://doi.org/10.1111/1 541-4337.12438.

13. Österberg J, Wingstrand A, Nygaard Jensen A, Kerouanton A, Cibin V, Barco $L$, Denis M, Aabo S, Bengtsson B, et al. Antibiotic resistance in Escherichia coli from pigs in organic and conventional farming in four European countries. PLoS One. 2016;11(6):e0157049. https://doi.org/10.1371/journal. pone.0157049.

14. Aparicio Tovar MA, Vargas Giraldo JD. Considerations on ethics and animal welfare in extensive pig production: breeding and fattening lberian pigs. Livest Sci. 2006;103(3):237-42. https://doi.org/10.1016/j.livsci.2006.05.010.

15. Mencía-Ares O, Argüello H, Puente H, Gómez-García M, Álvarez-Ordóñez A, Manzanilla EG, et al. Effect of antimicrobial use and production system on Campylobacter spp., Staphylococcus spp. and Salmonella spp. resistance in Spanish swine: A cross-sectional study. Zoonoses Public Health. 2020:1-13. https://doi.org/10.1111/zph.12790.

16. EMA. European Surveillance of Veterinary Antimicrobial Consumption (ESVA C) sales data and animal population data collection protocol (version 3). EMA/210691/2015-Rev.2. Amsterdam; 2019. https://www.ema.europa.eu/en/ documents/other/european-surveillance-veterinary-antimicrobialconsumption-esvac-web-based-sales-animal-population_en.pdf. Accessed 26 Feb 2021.

17. EUCAST. The European Committee on Antimicrobial Susceptibility Testing EUCAST. 2019. https://www.eucast.org/. Accessed 5 Jun 2019.

18. EUCAST. MIC and Inhibition zone diameter distributions of microorganisms without and with phenotypically evident resistance mechanisms. https:// mic.eucast.org/. Accessed 28 Nov 2020.

19. Magiorakos A-P, Srinivasan A, Carey RB, Carmeli Y, Falagas ME, Giske CG, Harbarth S, Hindler JF, Kahlmeter G, Olsson-Liljequist B, Paterson DL, Rice LB, Stelling J, Struelens MJ, Vatopoulos A, Weber JT, Monnet DL, et al. Multidrug-resistant, extensively drug-resistant and pandrug-resistant bacteria: an international expert proposal for interim standard definitions for acquired resistance. Clin Microbiol Infect. 2012;18(3):268-81. https://doi. org/10.1111/j.1469-0691.2011.03570.x.

20. Biocheck.UGent. https://biocheck.ugent.be/en. Accessed 16 Nov 2020.

21. Backhans A, Sjölund M, Lindberg A, Emanuelson U. Biosecurity level and health management practices in 60 swedish farrow-to-finish herds. Acta Vet Scand. 2015;57(1):14. https://doi.org/10.1186/s13028-015-0103-5.

22. Laanen M, Persoons D, Ribbens S, de Jong E, Callens B, Strubbe M, Maes D, Dewulf J, et al. Relationship between biosecurity and production/ antimicrobial treatment characteristics in pig herds. Vet J. 2013;198(2):50812. https://doi.org/10.1016/j.tvjl.2013.08.029.

23. Rodrigues Da Costa M, Gasa J, Calderón Díaz JA, Postma M, Dewulf J, McCutcheon G, et al. Using the Biocheck.UGent ${ }^{\text {TM }}$ scoring tool in Irish farrow-to-finish pig farms: Assessing biosecurity and its relation to productive performance. Porc Heal Manag. 2019;5:4. https://doi.org/10.1186/ s40813-018-0113-6.

24. OnlineEncuesta. https://www.onlineencuesta.com/. Accessed 12 Jun 2020.

25. R Core Team. R: A language and environment for statistical computing. 2019. https://www.r-project.org/.

26. Varga C, Rajić A, McFall ME, Avery BP, Reid-Smith RJ, Deckert A, Checkley SL, McEwen S, et al. Antimicrobial resistance in generic Escherichia coli isolated from swine fecal samples in 90 Alberta finishing farms. Can J Vet Res. 2008; 72(2):175-80.

27. Hollenbeck BL, Rice LB. Intrinsic and acquired resistance mechanisms in Enterococcus. Virulence. 2012;3(5):421-33. https://doi.org/10.4161/viru.21282.

28. Bates $\mathrm{D}$, Mächler $\mathrm{M}$, Bolker $\mathrm{B}$, Walker $\mathrm{S}$. Fitting linear mixed-effects models using Ime4. J Stat Softw. 2015;67:1-48. https://doi.org/10.18637/jss.v067.i01.

29. Barton K. MuMIn: Multi-Model Inference. R package version 1.43.6. 2019. https://cran.r-project.org/package=MuMIn.

30. Kolde R. pheatmap: Pretty Heatmaps. 2019. https://cran.r-project.org/packa ge=pheatmap.

31. Benjamini $Y$, Hochberg $Y$. Controlling the false discovery rate: a practical and powerful approach to multiple testing. J R Stat Soc Ser B. 1995;57(1): 289-300. https://doi.org/10.1111/j.2517-6161.1995.tb02031.x.

32. Harrell FE. Hmisc: Harrell miscellaneous. 2020. https://cran.r-project.org/pa ckage $=$ Hmisc.

33. FAO. Drivers, dynamics and epidemiology of antimicrobial resistance in animal production. Rome; 2016. https://www.fao.org/3/a-i6209e.pdf.

34. Von Wintersdorff CJH, Penders J, Van Niekerk JM, Mills ND, Majumder S, Van Alphen LB, et al. Dissemination of antimicrobial resistance in microbial ecosystems through horizontal gene transfer. Front Microbiol. 2016;7:173. https://doi.org/10.3389/fmicb.2016.00173.

35. Hesp A, Veldman K, van der Goot J, Mevius D, van Schaik G. Monitoring antimicrobial resistance trends in commensal Escherichia coli from livestock, the Netherlands, 1998 to 2016. Eurosurveillance. 2019;24(25):1800438. https://doi.org/10.2807/1560-7917.ES.2019.24.25.1800438.

36. Garcia-Migura L, Hendriksen RS, Fraile L, Aarestrup FM. Antimicrobial resistance of zoonotic and commensal bacteria in Europe: the missing link between consumption and resistance in veterinary medicine. Vet Microbiol. 2014;170(1-2):1-9. https://doi.org/10.1016/j.vetmic.2014.01.013.

37. Callens B, Cargnel M, Sarrazin S, Dewulf J, Hoet B, Vermeersch K, Wattiau P, Welby $\mathrm{S}$, et al. Associations between a decreased veterinary antimicrobial use and resistance in commensal Escherichia coli from Belgian livestock species (2011-2015). Prev Vet Med. 2018;157:50-8. https://doi.org/10.1016/j. prevetmed.2017.10.013.

38. Ceccarelli D, Hesp A, van der Goot J, Joosten P, Sarrazin S, Wagenaar JA, Dewulf J, Mevius DJ, et al. EFFORT consortium Antimicrobial resistance prevalence in commensal Escherichia coli from broilers, fattening turkeys, fattening pigs and veal calves in European countries and association with 
antimicrobial usage at country level. J Med Microbiol. 2020;69(4):537-47. https://doi.org/10.1099/jmm.0.001176.

39. Bager F, Madsen M, Christensen J, Aarestrup FM. Avoparcin used as a growth promoter is associated with the occurrence of vancomycinresistant Enterococcus faecium on Danish poultry and pig farms. Prev Vet Med. 1997;31(1-2):95-112. https://doi.org/10.1016/s0167-5877(96)0111 9-1.

40. Delsart M, Pol F, Dufour B, Rose N, Fablet C. Pig farming in alternative systems: strengths and challenges in terms of animal welfare, biosecurity, animal health and pork safety. Agriculture. 2020;10(7):261. https://doi.org/1 0.3390/agriculture10070261.

41. Murray AK, Zhang L, Snape J, Gaze WH. Comparing the selective and coselective effects of different antimicrobials in bacterial communities. Int J Antimicrob Agents. 2019;53(6):767-73. https://doi.org/10.1016/j.ijantimicag.2 019.03.001.

42. Min YH, Jeong JH, Choi YJ, Yun HJ, Lee K, Shim MJ, Kwak JH, Choi EC, et al. Heterogeneity of macrolide-lincosamide-streptogramin B resistance phenotypes in enterococci. Antimicrob Agents Chemother. 2003;47(11): 3415-20. https://doi.org/10.1128/AAC.47.11.3415-3420.2003.

43. EMA, CVMP, SAGAM. Reflection paper on the use of macrolides, lincosamides and streptogramins (MLS) in food-producing animals in the European Union: development of resistance and impact on human and animal health. London: European Medicines Agency; 2011. https://www. ema.europa.eu/en/documents/scientific-guideline/reflection-paper-use-ma crolides-lincosamides-streptogramins-mls-food-producing-animalseuropean en-0.pdf. Accessed 12 May 2020.

44. Lekagul A, Tangcharoensathien V, Yeung S. Patterns of antibiotic use in global pig production: a systematic review. Vet Anim Sci. 2019;7:100058. https://doi.org/10.1016/J.VAS.2019.100058.

45. WHO. WHO Guidelines on use of medically important antimicrobials in food-producing animals. Geneva; 2017. https://apps.who.int/iris/ bitstream/handle/10665/258970/9789241550130-eng.pdf. Accessed 18 Jul 2020.

46. Bender JK, Cattoir V, Hegstad K, Sadowy E, Coque TM, Westh $H$, Hammerum AM, Schaffer K, Burns K, Murchan S, Novais C, Freitas AR, Peixe L, del Grosso M, Pantosti A, Werner G, et al. Update on prevalence and mechanisms of resistance to linezolid, tigecycline and daptomycin in enterococci in Europe: towards a common nomenclature. Drug Resist Updat. 2018;40:25-39. https://doi.org/10.1016/ j.drup.2018.10.002

47. Postma M, Backhans A, Collineau L, Loesken S, Sjölund M, Belloc C, et al. Evaluation of the relationship between the biosecurity status, production parameters, herd characteristics and antimicrobial usage in farrow-to-finish pig production in four EU countries. Porc Heal Manag. 2016;2(1):9. https:// doi.org/10.1186/s40813-016-0028-z.

48. Backhans A, Sjölund M, Lindberg A, Emanuelson U. Antimicrobial use in Swedish farrow-to-finish pig herds is related to farmer characteristics. Porc Heal Manag. 2016;2(1):18. https://doi.org/10.1186/ s40813-016-0035-0.

49. Coyne LA, Latham SM, Dawson S, Donald IJ, Pearson RB, Smith RF, Williams $\mathrm{NJ}$, Pinchbeck GL, et al. Exploring perspectives on antimicrobial use in livestock: a mixed-methods study of UK pig farmers. Front Vet Sci. 2019;6: 257. https://doi.org/10.3389/fvets.2019.00257.

50. Postma M, Vanderhaeghen W, Sarrazin S, Maes D, Dewulf J. Reducing antimicrobial usage in pig production without jeopardizing production parameters. Zoonoses Public Health. 2017;64(1):63-74. https://doi.org/1 0.1111/zph.12283.

51. Martelli F, Lambert M, Butt P, Cheney T, Tatone FA, Callaby R, Rabie A Gosling RJ, Fordon S, Crocker G, Davies RH, Smith RP, et al. Evaluation of an enhanced cleaning and disinfection protocol in Salmonella contaminated pig holdings in the United Kingdom. PLoS One. 2017;12(6):e0178897. https://doi.org/10.1371/journal.pone.0178897.
52. Mannion C, Leonard FC, Lynch PB, Egan J. Efficacy of cleaning and disinfection on pig farms in Ireland. Vet Rec. 2007;161(11):371-5. https://doi. org/10.1136/vr.161.11.371.

53. Burns AM, Lawlor PG, Gardiner GE, McCabe EM, Walsh D, Mohammed $\mathrm{M}$, et al. Salmonella occurrence and Enterobacteriaceae counts in pig feed ingredients and compound feed from feed mills in Ireland. Prev Vet Med. 2015;121(3-4):231-9. https://doi.org/10.1016/j.prevetmed.2015. 07.002.

\section{Publisher's Note}

Springer Nature remains neutral with regard to jurisdictional claims in published maps and institutional affiliations.

\section{Ready to submit your research? Choose BMC and benefit from:}

- fast, convenient online submission

- thorough peer review by experienced researchers in your field

- rapid publication on acceptance

- support for research data, including large and complex data types

- gold Open Access which fosters wider collaboration and increased citations

- maximum visibility for your research: over $100 \mathrm{M}$ website views per year

At BMC, research is always in progress.

Learn more biomedcentral.com/submissions 